الثذبذب الحراري اليومي لدرجة حرارة التربة والهواء الجوي كدالة في الزمن والعمق

دراسة حالة لموجة البرد التي تعرضت لها منطقة الزاوية خلال الفترة 1 - 5 فبراير 1999

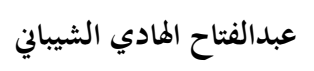

هيئة أبحاث العلوم الطبيعية والتكنولوجيا

afshibani@gmail.com

https://doi.org/10.36602/jmuas.2019.v01.01.12

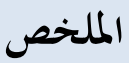

تعتبر درجة حرارة التربة من أهم المتغيرات اللازمة للدراسات الزراعية، ومن هنا تأتي أهمية القيام بدراستها وتحليلها، هناك مسألة هامة تتمثل في بعض التحديات التي تواجه العديد من الدراسات الزراعية التي تختص بدراسة حرارة التربة في ليبيا تتمثل تلك التحديات في الآتي، إن عملية

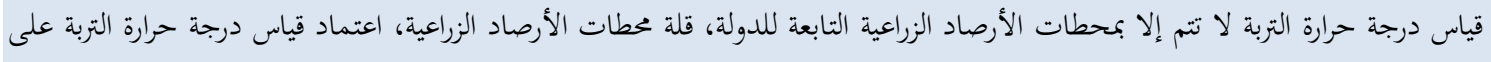
الخبرة العالية، قياس درجة حرارة أعماق التربة يتطلب استخدام عدة ترمومترات من نوع خاص، وهناك مسألة أخرى تتمثل في إمكانية القدرة

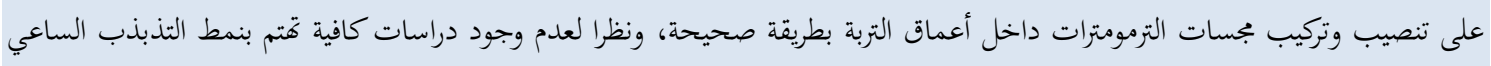

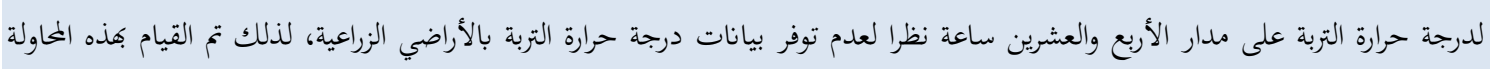

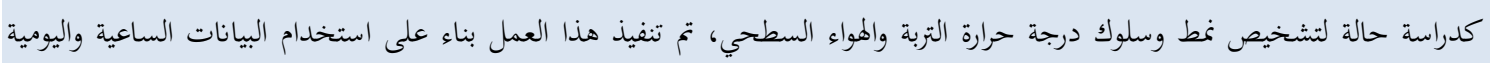

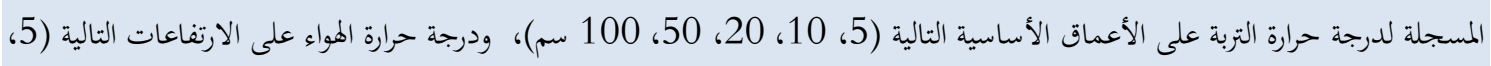

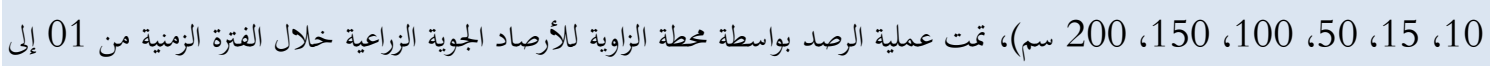

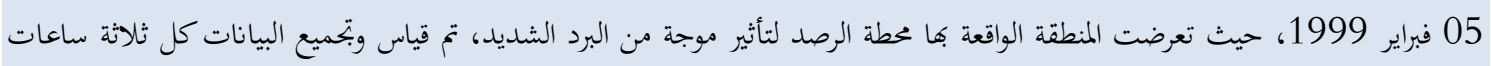

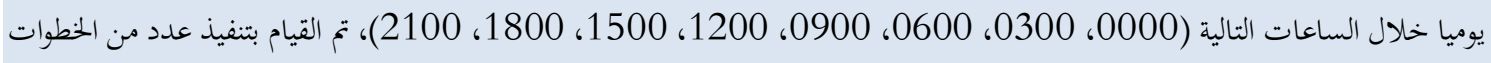
التحليلية مثل: استخدام قانون بيرسون لحساب معاملات الارتباط بين قيم درجة حرارة التربة الساعية ودرجة حرارة المواء الساعية المسجلة على ميلى

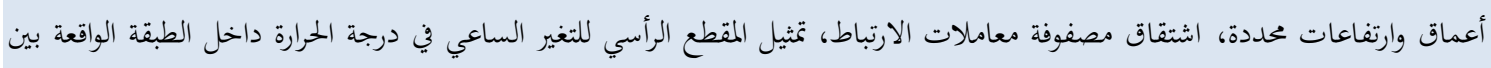

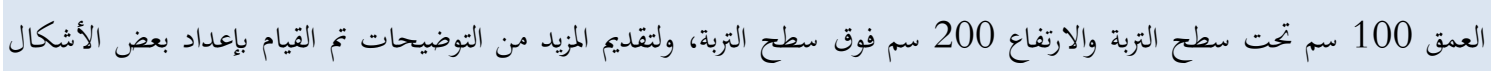

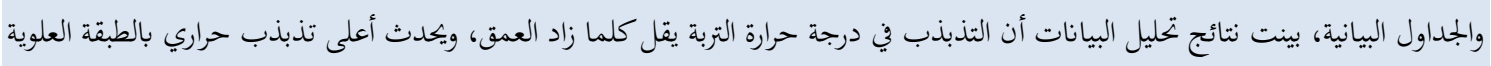

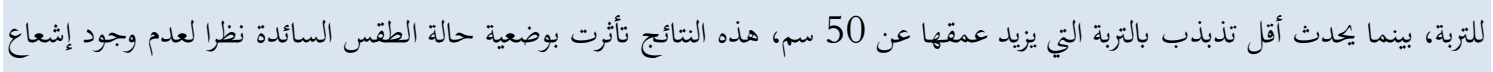

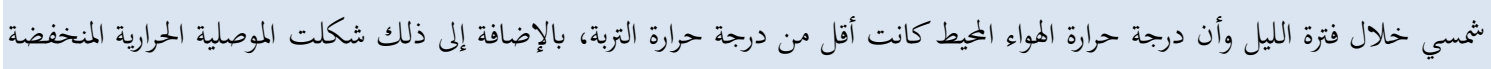

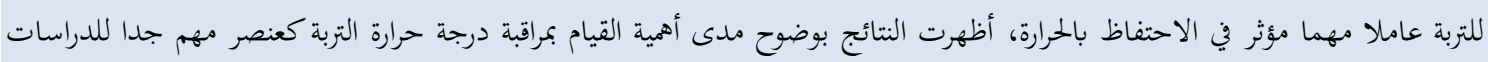

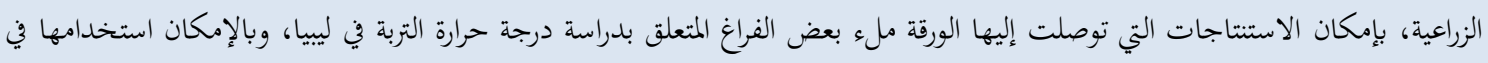
التخطيط الزراعي وتطبيقات حماية النبات. 
تعد بيانات درجة حرارة التربة Soil Temperature من المعلومات الأساسية في الدراسات الزراعية التطبيقية ولها أهمية كبيرة على مجمل نشاط النبات من حيث معدل النمو، امتصاص جذور النبات للماء، وسرعة تحلل المواد العضوية بالتربة وفعالية إمدادها للنبات بالعناصر الغذائية العضوية، ولحرارة التربة، ونمط تغيرها في الزمن والعمق، تأثير كبير في العمليات، الفيزيائية والكيميائية والبيولوجية، في نظام التربة (Hillel, D., 1982). يؤدي تذبذب حرارة التربة إلى انكماش معادها وتمددها وحدوث تغير في قوامها وخصائصها بدرجات متفاوتة، كما تؤثر حرارة التربة في النشاط الحيوي سواء كان نباتياً أو حيوانياً، فإذا الخخضت درجة حرارة التربة عن الصفر الحيوي، أو ما يقارب الخمس درجات مئوية فوق الصفر توقف النشاط الحيوي في التربة، وعند ارتفاع درجة حرارة التربة تزداد فعالية الأحياء التي بدورها تزيد من سرعة تحلل المادة العضوية وتوفير العناصر الغذائية العضوية للنبات،(Hanks, R. J., 1992)، تقاس درجة حرارة التربة بواسطة ترمومترات الأعماق تبعا لنوع التربة والمحاصيل المزروعة، وتستخدم درجة حرارة أعماق التربة في دراسات علم الأرصاد الجوية الزراعية وهو العلم الذي يربط بين عناصر الطقس والمناخ والعلوم الزراعية، يختص هذا العلم برصد ودراسة الطبقة الواقعة بين عمق ثلاثة أمتار تحت سطح التربة التي تحتوي على جذور النبات، ويمتد حتى الطبقة الحدية من الهواء الجوي التي تحتوي على المحاصيل، ثم الطبقة الحيوية التي تنتقل خلالما حبوب اللقاح والبذور والأمراض والآفات الزراعية، وعلى هذا الأساس تأتي أهمية التعرف على الحصائص الفيزيائية للتربة والتي من بينها درجة الحرارة، تنتقل الطاقة الحرارية في التربة بعدة آليات مثل: ـ آلية التوصيل Heat Conduction والتي تعمل على انتقال الطاقة خلال التربة، نتيجة لنشاط جزيئاما، من الجزء الأعلى حرارة، إلى الجزء الأقل حرارة، لذلك يتوقف معدل انتقال الحرارة بالتوصيل على نوعية التربة ومدى اختلاف درجة الحرارة بين طبقاتها التي تتدفق بينهما الطاقة الحرارية. ـ آلية الحمل Heat Convection تتمثل هذه الآلية في انتقال الجسم الحامل للطاقة الحرارية من مكانه إلى مكان آخر الأمر الذي يتحقق في نظام التربة، بواسطة السوائل والغازات التي تتحرك فيها من خلال مسامها، فحينما تسقط الأمطار مثلاً، على سطح التربة ثم تتغلغل في مسامها فإنها تحمل جزءاً من الطاقة الحرارية من الجزء العلوي للتربة إلى جزئها السفلي. ـ آلية الإشعاع Heat Radiation وبهذه الآلية تنتقل الطاقة الحرارية من الجسم الأعلى حرارة إلى الجسم الأقل حرارة بدون أن يتماسّا أو يتحركا؛ إذ أن الطاقة الحرارية لجسم معين تتحول إلى طاقة كهرومغناطيسية على السطح تنقلها الموجات ، الإشعاعية في الفضاء وتتحول إلى طاقة حرارية عندما تصطدم بسطح جسم آخر، (Hillel, D,. 1980) (108)

.(Marshall, T. J. and others, 1988) ـ التوصيل الحراري للتربة Heat Conductivity والذي يعني مقدار الطاقة الحرارية المنقولة خلال وحدة مساحة معينة منها، خلال وحدة زمن، تحت فارق في درجة الحرارة، بين نقطتين متباعدتين وحدة مسافة واحدة، مقدار درجة حرارة 
واحدة(Farouki, O. T., 1986)، يؤدي اختلاف مكونات التربة إلى اختلاف قدرتا على التوصيل الحراري، لذلك يعتمد التوصيل الحراري للتربة على أنواع المعادن المكونة لما ومحتواها من المادة العضوية ومساميتها ومحتواها من الرطوبة، وهذا يتغير بتغير نسب الماء والهواء فيها، كما أن اختلاف تركيب التربة في العمق يجعل توصيلها الحراري متغيراً، إذن التوصيل الحراري للتربة هو دالة في العمق والزمن، (Hanks, R. J., 1992). هناك العديد من الدراســـات التي تناولت موضـــوع تذبذب درجة حرارة التربة على أعماق مختلفة وتأثيرها على النباتات

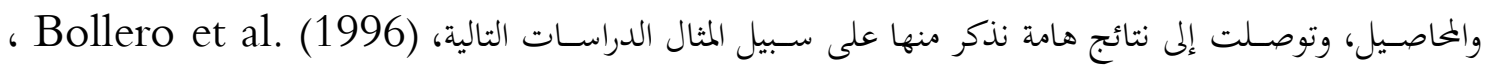
تلخصـت النتائج التي توصـل إليها في أن الذبذبات الحادة في حرارة التربة تؤثر بشـكل مباشـــ على نمو المحاصسيل الزراعية ومعدلاقما الإنتاجية، وبين أن حرارة الطبقات الضحلة للتربة أثناء فصل الربيع البارد تؤدي إلى تأخير نمو نبات الذرة، بينما أثناء فصل الربيع الدافئ تؤدي حرارة التربة إلى زيادة محصول الذرة، واستنتج أيضا أن درجة حرارة التربة الدافئة تعمل على كلى Al- et al. تمفيز وتنشيط نمو أوراق النبات ما يؤثر بشكل كبير على معدل التبخر من مياه التربة الحقلية، (1990) Rawi وتقلل من حجم الفاقد من البذور المزروعة ويحصـل العكس أثناء انخفاض درجة حرارة التربة حيث تكون عملية الإنبات بطيئة ومتدنية ويزداد حجم الفاقد من البذور نتيجة درجة الحرارة غير الملائمة لعملية إنبات البذور، إذ لا يقتصر تأثير درجة حرارة التربة على إنبات البذور بل يؤثر في الأطوار الأخرى لنمو النبات إذ عند الخفاضــها عن الحد الأدنى تئدي إلى بتمد الماء داخل الجذور النباتية ويؤدي هذا إلى ذبول النبات لأنهُ يعجز عن حصــوله على الماء الذي يحتاج إليه لإتمام العمليات الحيوية، وينتج عن ذلك تعطل نشاط الجذور وموتا، (1989) . Ali, A. et al استنتج أن درجة حرارة التربة تؤثر في عملية إنبات البذور، إذ كلما ارتفعت درجة حرارة التربة انخفض عدد الأيام اللازمة للإنبات وبالعكس كلما انخفضــت حرارة التربة احتاجت البذور إلى مدة أطول للإنبات، (Gawad et al. لاحظ (1989) أن درجة حرارة التربة تتأثر بلون التربة ويؤثر ذلك تأثيراً مباشراً في نمو النبات من خلال تأثير لون التربة في تغيرات درجة الحرارة، فاللون الأسـود القاتم يمتص قدراً أكبر من درجة الحرارة عن اللون الفاتح، لأن الأخير يعكس أشعة الشـمس، عكس اللون الأسود القاتم الذي يمتص الأشعة بصورة أسرع وأكثر، لذا يمكن اتخاذ اللون القاتم دليلاً عن القدرة الإنتاجية للأرض، إذ تكون خصبة بمادما العضـوية (الدبال) ولها القدرة على الاحتفاظ بالماء ودرجة الحرارة، (1988) .Al-Ani، لاحظ تأثر سـرعة فقدان الماء من النبات بصـورة غير مباشـرة بدرجة حرارة التربة، فسرعة النتح تعتمد على سـرعة امتصـاص التربة للماء، وتزداد الأخيرة

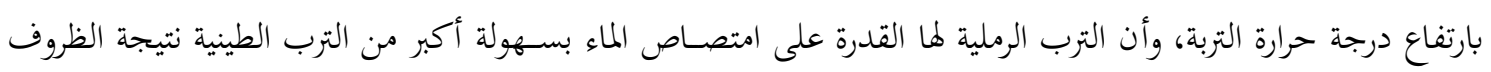
اللاهوائية المختزلة في الأخير، أما على المستوى المحلي فلم يعثر الباحث على أية دراسـات تناولت موضسوع دراسـة وتحليل

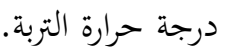




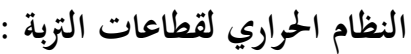

درجة حرارة التربة ليست ثابتة فهي تتغير باستمرار تبعا للتغير المستمر في أحوال الطقس، ويعتبر التغير المستمر لدرجة حرارة التربة على التعاقب الدوري المنتظم لها الذي يحدث على المدى اليومي والسنوي، وهذه الدورات اليومية والسنوية لدرجة حرارة التربة تتميز بالتغير بسبب ما يعتريها من ظواهر عرضية غير منتظمة، مثل : موجات البرد والصقيع، وموجات الحر، والسحب، والأمطار الشديدة، والعواصف الثلجية، وفترات الجفاف، وبإمكان التغير في خواص التربة نفسها إحداث تغير في نمط الدورة اليومية والسنوية، لدرجة حرارتا، ومن أهم خواص التربة، ذات التغيرات المؤقتة انعكاسية الأشعة من السطح (الالبيدو)، والسعة الحرارية، والتوصيل الحراري. ويعد النظام الحراري لقطاعات التربة نظاماً مفتوحاً لأنه يتبادل كلاً من الطاقة والمادة مع الأنظمة الأخرى مثل المواء الجوي والطبقات الأرضية تحت قطاع التربة (Rezuana Islam, 2017) ، ولهذا يمكن تمثيل تذبذب درجة حرارة التربة عند أعماقها المختلفة كدالة توافقية في الزمن حول قيمة متوسطة، تعرضت (منطقة الدراسة) إلى موجة برد شديدة خلال الفترة الممتدة من يوم 01 إلى يوم 05 فبراير 1999، ووفقا لبيانات درجات الحرارة التي تم رصدها بواسطة محطة الزاوية للأرصاد الزراعية انخفضت درجة الحرارة السطحية إلى 4.2 درجة مئوية تحت الصفر خلال يوم 02 فبراير (الجدول رقم 1)، وفي اليوم الذي قبله واليوم الذي يليه الخفضت إلى صفر درجة مئوية، تميزت حالة الطقس بالصقيع والبرودة الشديدة، وقلة السحب، وضعف حركة الرياح، تراوح المتوسط اليومي للرطوبة النسبية بين 73 \% إلى 86 \%، ونظرا لتوفر قياسات درجات الحرارة الساعية لطبقة التربة السطحية حتى عمق واحد متر إضافة إلى قياسات الحرارة لطبقة الهواء الملاصقة لسطح التربة حتى ارتفاع مترين فقد تم التركيز على القيام بإجراء دراسة حالة تستند على تحليل بيانات الرصد وذلك لتشخيص نمط التذبذب اليومي في المقطع الرأسي لدرجات حرارة التربة والطبقة المحية للهواء الجوي الملاصق لسطح التربة وتحديد العوامل المؤثرة التي سادت خلال تلك الفترة، وذلك تحت تأثير موجة البرد والصقيع التي تعرضت لها منطقة الزاوية، يمكن تعريف الموجات الباردة بأها هبوط واضح في درجة حرارة المواء فوق منطقة معينة، أو غزو هواء شديد (Smith, البرودة لمذه المنطقة، وفي الغالب تقترن الموجات الباردة بتقلبات في عناصر الطقس، مثل الصقيع وتساقط البرد ( E. T., 2018) وتترافق بحدوث انخفاض حاد ومفاجئ في درجات الحرارة عن ما هو معتاد عليه في المنطقة المعنية، وتعتمد على المعدل العام الشهري الذي تحدث فيه الموجة.

\section{أهداف الدراسة.}

تركزت الأهداف الرئيسية للدراسة حول القيام بتشخيص الحالة من خلال المحاور التالية:

1. تحديد العلاقة بين درجات الحرارة الساعية لأعماق التربة على الارتفاعات القريبة من السطح، (الهواء السطحي). 2. التعرف على مدى التأثير الحراري المتبادل بين أعماق التربة وطبقة الهواء الملاصق لها. 
3ـ الكشف على سلوك ونمط التذبذب في درجة حرارة التربة تحت تأثير موجة البرد.

4. تصميم شكل لنمط تردد الموجة الحرارية المؤثرة (حرارة الهواء السطحي)، ونمط تردد الموجة الحرارية المنتقلة (حرارة التربة (السطحية). 5. تأثير حالات البرد والصقيع على النباتات والمحاصيل الزراعية، وطرق حماية النبات من تأثيرات الخفاض درجة حرارة التربة.

الجحدول (1) درجات الحرارة المسجلة بواسطة محطة الزاوية للأرصاد الزراعية على ارتفاع 5 سنتيمترات فرق سطح التربة.

\begin{tabular}{|c|c|c|c|c|c|}
\hline \multicolumn{6}{|c|}{ درجة حرارة المواء الجوي المسجلة على ارتفاع 5 سنتيمترات فرق سطح التربة } \\
\hline $1999 / 2 / 5$ & $1999 / 2 / 4$ & $1999 / 2 / 3$ & $1999 / 2 / 2$ & $1999 / 2 / 1$ & توقيت الرصد \\
\hline 07.2 & 0 p 06.5 & 01.0 & ${ }^{0}{ }_{p} 02.0-$ & 04.3 & 0000 \\
\hline 07.1 & 06.0 & 00.0 & 03.1 - & 02.3 & 0300 \\
\hline 07.0 & 06.8 & 02.8 & ${ }^{0}, 04.2$ - & 01.0 & 0600 \\
\hline 08.0 & 08.0 & 07.7 & ${ }^{0}>11.0$ & 10.5 & 0900 \\
\hline 10.3 & 09.0 & 0 & ${ }^{0}, 17.3$ & 15.5 & 1200 \\
\hline 0 ; 14.3 & Po 09.8 & 0 & $0,15.2$ & 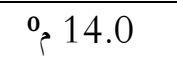 & 1500 \\
\hline 08.3 & 07.0 & 07.8 & $0,01.2$ & 01.8 & 1800 \\
\hline 01.0 & 06.0 & 07.0 & 02.5 & ${ }^{0}>01.3-$ & 2100 \\
\hline
\end{tabular}

المصدر: الباحث

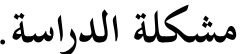

تعد بيانات درجة حرارة التربة من المعلومات الأساسية اللازم توفرها للدراسات الزراعية التطبيقية نظرا لأهمية التعرف على تأثير حرارة التربة على بجمل مراحل نمو النبات، وعلى الرغم من ذلك لا توجد في ليبيا دراسات كافية هتم بنمط التذبذب الساعي لدرجة حرارة التربة على مدار الأربع والعشرين ساعة نظرا لعدم وجود قياسات كافية على نطاق واسع لدرجة حرارة التربة بالأراضي الزراعية، ويرجع ذلك إلى وجود بعض الأسباب التي باتت تمثل نوعا من التحديات التي تواجه الباحثين في هذا المجال، تتمثل تلك التحديات في محدودية عمليات رصد درجة حرارة التربة واقتصارها على محطات الأرصاد الجوية الزراعية التابعة للدولة القليلة جدا، اعتماد قياس درجة حرارة التربة على الخبرة العالية، قياس درجة حرارة أعماق التربة يتطلب استخدام عدة ترمومترات من نوع خاص، وهناك مسألة أخرى تتمثل في إمكانية القدرة على تنصيب وتركيب بجسات 
الترمومترات داخل أعماق التربة بطريقة صحيحة، إضافة إلى عدم توفر معطات الرصد الآلي، وعلى هذا الأساس تم القيام بهذه الدراسة لتشخيص نمط وسلوك درجة حرارة التربة والهواء السطحي.

\section{البيانات ومنطقة الدراسة:}

اعتمدت الدراسة على تحليل بيانات درجات الحرارة اليومية التي تم رصدها بواسطة محطة الزاوية للأرصاد الجوية الزراعية الواقعة على الإحداثيات التالية، (خط عرض 32:45 شمالا، خط طول 12:45 شرقا)، تضمنت عملية الرصد قياس وتسجيل درجة حرارة التربة على الأعماق التالية، (5، 10، 20، 50 و 100 سم)، تحت سطح التربة، إضافة إلى قياس تسجيل درجة حرارة الهواء على الارتفاعات التالية، (5، 10، 15، 50، 100، 150 و 200 سم)، فوق سطح التربة، وذلك بواقع ثمان رصدات يوميا خلال الساعات التالية، (0000، 0300، 0600، 0900، 1200، 1500، 1800، 2100). وكانت عملية الرصد قد تمت خلال الفترة الزمنية الممتدة من 01 إلى 05 فبراير 1999.

\section{نوعية التربة بمنطقة الدراسة}

رملية خفيفة يتراوح قطر حبيباتا بين 0.02 و2.0 مليمتر، ويتراوح سمك طبقة التربة السطحية بين 10 و 20 متر، لوها بني أصفر، وهي تحتوي على صخور وحصى صغيرة، وتحتوي على نسبة من الطين تتراوح ما بين 1 و 5 \%؛، ويتراوح قطر حبيبات الطين بين 0.002 و 0.02 ملليمتر، وتصنف تربة المنطقة بأها تربة غير ناضجة ومفككة وسهلة التسرب، وهي سهلة التأثر بفعل التعرية الموائية ما لم يتم حمايتها بغطاء نباتي، [El-hjaji, S. A., (1989).

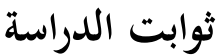

لتعيين كيفية توزيع درجات الحرارة خلال أعماق التربة تم افتراض ثبات العناصر التالية: موقع الدراسة - محطة الزاوية للأرصاد الجوية الزراعية. نوعية التربة - رملية طينية مزجية.

الظلال المتوفرة في موقع الدراسة - منطقة معرضة للشمس خلال ساعات اليوم الواحد. للمحافظة على مستوى رطوبة ثابت بموقع الدراسة - تم تجنب السقي أو مرور الماء السطحي خلال مساحة موقع الرصد البالغة نحو 25 متر مربع تقريبا. اقتصار الدراسة على فترة تأثر المنطقة بموجة البرد - خمسة أيام بداية من يوم 1 إلى يوم 5 فبراير 1999. دراسة التوزيع الحراري اليومي بالمقطع الرأسي حول سطح التربة - للطبقة الواقعة بين العمق 100 سم تحت سطح التربة و الارتفاع 200 سم فوق سطح التربة. 
استخدام أجهزة القياس - ترمومترات قياس درجة حرارة أعماق التربة ذات السيقان المنحنية التي تعتمد على تمدد وانكماش سائل الزئبق داخل أنبوب زجاجي مدرج، تم دفن مستودعات الترمومترات بالأعماق القياسية للتربة بحيث تكون تدريجاتا متجهة للأعلى مع بتجب ترك أي جزء من الساق الظاهر للترمومتر معرض لأشعة الشمس.

\section{متغيرات الدراسة:}

استندت الدراسة على الفرضيات التالية:

1ـ التوزيع الساعي لدرجة حرارة طبقة التربة بداية من السطح إلى العمق واحد متر، وفق الترتيب التالي، درجة حرارة العمق

$$
5 \text { سم، } 10 \text { سم، } 20 \text { سم، } 50 \text { سم و } 100 \text { سم. }
$$

2. مدة القياس يوميا، من الساعة 0000 توقيت عالمي حتى الساعة 2100 .

3ـ الفترات الفاصلة لتسجيل القراءات كل ثلاثة ساعات، بمعدل ثمانية قراءات يوميا.

4ـ تقسيم طبقة التربة إلى طبقتين، الطبقة الأولى تبدأ من السطح حتى العمق 20 سم، الطبقة الثانية تبدأ بعمق أكبر من

$$
20 \text { سم وتمتد حتى العمق } 100 \text { سم. }
$$

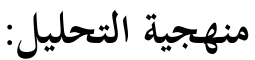

تلخصت منهجية التحليل في تنفيذ عدد من الخطوات تم ترتيبها على النحو التالي: الخطوة الأولى: تحديد العلاقة بين درجات الحرارة الساعية لأعماق التربة ومستويات (ارتفاعات) الهواء السطحي، تم حساب (Thom, H.C.S. 1996), (Wilks, . قيم معاملات الارتباط باستخدام قانون ارتباط بيرسون، المعادلة رقم 1 (Tho (Storch, H. V 2001),(Islam K., Khan, A. and other, . 2015) D.S. 2001),

$$
r=\frac{\sum_{i=1}^{n} x y}{\sqrt{\sum_{i=1}^{N} x^{2} \sum_{i=1}^{N} y^{2}}}
$$

حيث أن X و Xتمثلان قيم درجات الحرارة لطبقتي التربة والهواء المسجلة عند أعماق التربة كمتغير والارتفاعات التي تم عندها قياس درجة الحرارة كمتغير أيضا، وعلى أساس هذه المعادلة تم تحديد مصفوفة معاملات الارتباط بين المتغيرين، والغرض من إجراء هذه الخطوة هو التعرف على مدى التأثير الحراري المتبادل بين أعماق التربة وطبقة الهواء الملاصق لها، إذا كانت معاملات الارتباط عالية فإن ذلك يعنى وجود ارتباط قوي يدل على وجود تأثير متبادل بين المتغيرين (الأعماق والارتفاعات)، أما إذا كانت قيم معاملات الارتباط صغيرة أو سلبية فإن ذلك يعنى أن الارتباط ضعيف ويدل على عدم وجود تأثير متبادل بين الأعماق والارتفاعات، وبما أن كل قيمة من قيم معاملات الارتباط بالمصفوفة تمثل قيمة الارتباط بين (متغيرين) عمقين 
أو ارتفاعين أو عمق وارتفاع، والتي تم حساها على أساس قيم درجات الحرارة الساعية للمتغيرين، وبذلك تم استخدام عدد 80 زوجاً لكل قيمة من قيم الارتباط الموجودة بالمصفوفة، ووفق جداول فيشر لتحديد القيمة الحرجة لمعامل الارتباط بين

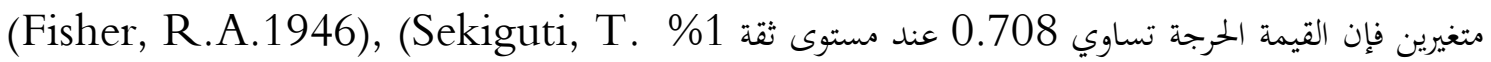
(1952 ، وعلى هذا الأساس فإن قيم معاملات الارتباط بين المتغيرات التي تساوي 0.708 أو أعلى تدل على وجود تأثير متبادل بينهما، أما تلك القيم التي تقل عن 0.708 فهي تدل على عدم وجود علاقة قويه بين المتغيرات المعنية وبالتالي يمكن استنتاج عدم وجود تأثير متبادل بينهما بشكل فعال.

الخطوة الثانية: للتعرف على نظام التذبذب الحراري الساعي لقطاع التربة والهواء الملاصق لما بهدف الكشف على سلوك ونمط التغير في درجة حرارة التربة تحت تأثير موجة البرد تم التركيز على نوعين من التغيرات، التغير مع الزمن، والتغير مع العمق، تم تمثيل بيانات درجات الحرارة التي تم رصدها خلال فترة الدراسة على هيئة شكل مخطط شبكي يمثل المقطع الرأسي للتربة السطحية وطبقة المواء الملاصقة لما، يتكون هذا المخطط الشبكي من محورين رأسي وأفقي، المحور الرأسي يمثل عدد 12 مستوى قياس، خمسة منها تحت سطح التربة وسبعة فوق سطح التربة، حيث تم ترتيبها من الأسفل إلى الأعلى على النحو التالي، مستويات قياس درجة حرارة التربة على الأعماق 100، 50، 20، 10، و 5 سم، ومستويات قياس درجة حرارة الهواء فوق سطح التربة على الارتفاعات 5، 10، 15، 50، 100، 150، و 200 سم. أما المحور الأفقي فهو يمثل فترة القياس بالساعات ابتداء من الساعة 0000 ليوم 01 فبراير 1999 ، حتى الساعة 2100 ليوم 04 فبراير 1999، وهذا المحور يمثل جميع الساعات التي تمت فيها عمليات رصد درجات حرارة الأعماق والارتفاعات والتي بلغ عددها 38 رصدة بواقع ثمان رصدات يوميا، ونظر لازدحام البيانات على هذا المحور لم يتم تضمين بيانات اليوم الخامس إضافة إلى أن موجة البرد خلال هذا اليوم بدأت في الانقشاع، وتم توقيع قيم درجات الحرارة على نقاط التقاطع بين محوري مستويات القياس وساعات القياس، مستويات القياس (عمق أو ارتفاع)، الذي تم قياس درجة الحرارة عندها، وساعات الرصد التي تمت فيها عملية القياس والرصد، وعلى هذا الأساس تم تحليل إيقاع التذبذب اليومي والساعي لدرجة حرارة المقطع الرأسي لطبقتي التربة والهواء الجوي الواقعين بين عمق التربة 100 سم، والارتفاع 200 سم فوق سطح التربة، وذلك باتباع طريقة رسم خطوط الربط أو التوصيل Isolines بين جميع النقاط التي تتساوى فيها درجة الحرارة Isothermal Lines بحيث يتخلل فاصل بين الخط والخط المجاور له (تدرج حراري) بقيمة 2 درجة مئوية، وبناء على ذلك تم تكوين صورة مقطعية للتعاقب الدوري للفترات التي الخفضت فيها درجات الحرارة إلى أدنى قيمة ومدى تغلغلها داخل أعماق التربة، والفترات التي ارتفعت فيها درجات الحرارة إلى أقصى قيمة ومدى تغلغلها داخل أعماق التربة، وحتى يتم التمكن من تضمين جميع خطوط تساوي درجات الحرارة خلال هذا المقطع تمت عملية الرسم بطريقة يدوية وذلك لتوخي دقة التحليل. 
الخطوة الثالثة: تصميم شكل بياني لتوضيح مدى الاختلاف بين نمط تردد الموجة الحرارية المؤثرة في التربة (حرارة المواء السطحي)، ونمط تردد الموجة الحرارية المنتقلة من الهواء إلى التربة (حرارة التربة السطحية). الخطوة الرابعة: لزيادة التوضيح تم تحويل البيانات إلى أشكال بيانية وتلخيص جزء منها على هيئة جداول.

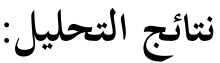

نستخلص من التحاليل التي تم إجراؤها الآتي: بينت معاملات الارتباط بين قيم درجات الحرارة الساعية للهواء الجوي القريب من سطح التربة ودرجات الحرارة الساعية لأعماق التربة وجود تباين ملحوظ بين قيم معاملات الارتباط التي تراوحت بين أعلى قيمة 0.994 وهي تمثل ارتباط إيجابي قوي بين درجات حرارة الهواء عند المستويين 10 سم، 50 سم، وأقل قيمة 0.315 وهي تمثل ارتباط سلبي ضعيف بين درجات حرارة الهواء عند المستوى 100 سم ودرجات الحرارة عند عمق التربة 50 سم، وتم ترتيب قيم معاملات الارتباط بين كافة الارتفاعات والأعماق على هيئة مصفوفة كما هو مبين بالجدول (2)، الذي يمثل مصفوفة قيم معاملات الارتباط بين هاذين المتغيرين، وعلى هذا الأساس تم استخلاص ثلاثة أنواع من الارتباط

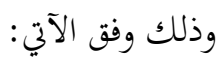

النوع الأول: الارتباط بين عمقين: الارتباط بين حرارة التربة بالأعماق التي تم عندها الرصد، تراوحت قيم الارتباط بين أعلى قيمة 0.964 للعمقين 5 سم و 10 سم، وأقل قيمة - 0.279 بين العمقين 5 سم و 50 سم، وكانت قيم معاملات الارتباط التي كانت قريبة جدا من الصفر على النحو التالي: بلغت قيمة معامل الارتباط - 042 بين حرارة عمقي التربة 20 سم و 50 سم، وبلغت - 053 0.00 بين حرارة عمقي التربة 5 سم و 100 سم، وهي تدل على درجات عالية من التباين والتفاوت بين درجة حرارة الأعماق حيث تكون درجة الارتباط عالية بين الأعماق القريبة من بعضها، ويتبين من ذلك وجود ارتباط عالي بين حرارة طبقة التربة المحصورة بين الأعماق 5 و 20 سم، كما أنه يكون عاليا أيضا بين حرارة التربة المحصورة بين الأعماق 50، و 100 سم، مع وجود ارتباط عكسي بين حرارة الطبقتين، وهذا يبين أن المؤثرات

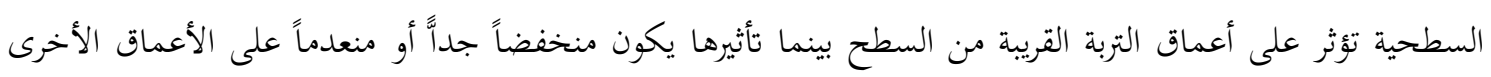
ابتداء من 50 سم. النوع الثاني: الارتباط بين ارتفاعين: الارتباط بين حرارة المواء للارتفاعات التي تم عندها الرصد، تراوحت قيم الارتباط بين أعلى قيمة 0.994 للارتفاعين 10سم و 50سم، وأقل قيمة 0.887 للارتفاعين 15سم و 200سم، وهي في المجمل قيم ارتباط عالية تدل بوضوح على التماثل والتوصيل الحراري لطبقة الهواء الواقعة بين الارتفاعات 5سم و 200سم. النوع الثالث: الارتباط بين عمق وارتفاع: الارتباط بين حرارة أعماق التربة وحرارة الهواء عند الارتفاعات التي تم عندها الرصد تراوحت بين أعلى قيمة 0.794 للعمق 5سم والارتفاع 5سم، وأقل قيمة - 0.315 للعمق 50سم والارتفاع 
عدد خاص بالأوراق العلمية المقدمة للمؤتمر العلمي الأول للعلوم الزراعية - إنتاج نباتي (5-6 أكتوبر 2019)

100سم، أيضا كانت قيمة معامل الارتباط قريبة من الصفر (0.065) بين الارتفاع 15سم وعمق التربة 20سم، وهذا يكشف عن وجود اختلاف في نمط التغير اليومي لدرجة حرارة الهواء والتربة وذلك يرجع إلى مدى الاختلاف بين درجة التأثر بالعوامل البيئية كالإشعاع والرياح والرطوبة.

الجدول (2) مصفوفة معامل الارتباط بين درجات الحرارة المسجلة عند الارتفاعات والأعماق

\begin{tabular}{|c|c|c|c|c|c|c|c|c|c|c|c|c|}
\hline \multicolumn{5}{|c|}{ الأعماق تحت سطح التربة (سنتيمتر) } & \multicolumn{7}{|c|}{ الارتفاعات فوق سطح التربة (سنتيمتر) } & \multirow{2}{*}{ بصن حوارة الهواء } \\
\hline 100 & 50 & 20 & 10 & 5 & 5 & 10 & 15 & 50 & 100 & 150 & 200 & \\
\hline $\mathbf{c m}$ & cm & $\mathbf{c m}$ & $\mathbf{c m}$ & $\mathbf{c m}$ & cm & cm & $\mathbf{c m}$ & $\mathbf{c m}$ & $\mathbf{c m}$ & cm & $\mathrm{Cm}$ & \\
\hline $0.172-$ & 0.264 - & 0.257 & 0.686 & 0.788 & 0.960 & 0.995 & 0.887 & 0.964 & 0.968 & 0.936 & 1 & 200 سم هواء \\
\hline 0.176 - & 0.301 - & 0.172 & 0.644 & 0.762 & 0.970 & 0.962 & 0.968 & 0.970 & 0.973 & 1 & 0.936 & 150 سم هواء \\
\hline 0.201 - & 0.315 - & 0.223 & 0.686 & 0.793 & 0.993 & 0.986 & 0.943 & 0.994 & 1 & 0.973 & 0.968 & 100 سم هواء \\
\hline 0.171 - & $0.281-$ & 0.216 & 0.676 & 0.780 & 0.993 & 0.994 & 0.942 & 1 & 0.994 & 0.970 & 0.964 & 50 سم هو اء \\
\hline 0.110 - & $0.261-$ & 0.056 & 0.590 & 0.700 & 0.948 & 0.937 & 1 & 0.942 & 0.943 & 0.968 & 0.887 & 15 سم هواء \\
\hline 0.129 - & 0.227 - & 0.234 & 0.681 & 0.784 & 0.987 & 1 & 0.937 & 0.994 & 0.986 & 0.962 & 0.955 & 10 سم هواء \\
\hline 0.156 - & $0.289-$ & 0.203 & 0.684 & 0.794 & 1 & 0.987 & 0.948 & 0.993 & 0.993 & 0.970 & 0.960 & 5 سم هو اء \\
\hline 0.139 - & $0.279-$ & 0.689 & 0.964 & 1 & 0.794 & 0.784 & 0.700 & 0.780 & 0.793 & 0.762 & 0.788 & 5 سم تربة \\
\hline 0.121 - & $0.247-$ & 0.780 & 1 & 0.964 & 0.684 & 0.681 & 0.569 & 0.676 & 0.686 & 0.644 & 0.686 & 10 سم تربة \\
\hline 0.053 - & $0.042-$ & 1 & 0.780 & 0.689 & 0.203 & 0.234 & 0.056 & 0.216 & 0.223 & 0.172 & 0.257 & 20 سم تربة \\
\hline 0.864 & 1 & $0.042-$ & $0.247-$ & $0.279-$ & $0.289-$ & $0.227-$ & $0.261-$ & 0.281 - & $0.315-$ & $0.301-$ & $0.264-$ & 50 سم تربة \\
\hline 1 & 0.864 & $0.053-$ & $0.121-$ & $0.139-$ & $0.156-$ & 0.129 - & $0.110-$ & $0.171-$ & 0.201 - & $0.176-$ & $0.172-$ & 100 سم تربة \\
\hline
\end{tabular}

المصدر: الباحث

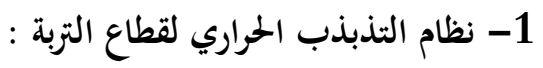

للتعرف على نظام التذبذب الحراري لقطاع التربة تم تمثيل بيانات درجة حرارة التربة لمختلف الأعماق خلال فترة تأثر منطقة الدراسة بموجة البرد كما هو مبين بالشكل (1)، والذي من خلاله يتضح أن التذبذب الحراري اليومي للتربة يتسم بنوعين من التذبذبات هما، التذبذب الحراري مع العمق والتذبذب الحراري مع الزمن. 1.1 - 2 - 1 التذبذب الحراري مع العمق:

يتبين من الشكل (1)، أن درجات حرارة أعماق التربة تتذبذب بصورة أبطأ وأقل بكثير من درجة حرارة الهواء الجوي الواقع فوق سطح التربة، ولذذا فإن درجة الحرارة العظمى للتربة تكون أقل مما هي عليه في الهواء خلال ساعات النهار بينما تكون درجة الحرارة الصغرى للتربة أعلى مما هي عليه في الهواء خلال ساعات الليل، ومن خلال تحليل مخطط المقطع الرأسي، الشكل (1)، نلاحظ وجود نوعين من التذبذبات في درجات حرارة أعماق التربة: 1ـ تذبذب يحدث في الطبقة السطحية القريبة من سطح التربة وهو تذبذب قوي يمتد حتى العمق 20سم أو أكثر. 
2 تذبذب ضعيف يقل كلما زاد العمق بحيث يبدأ في الاختفاء عند عمق 50سم ويختفي تماما عند عمق 100سم. وتحتاج عملية تغلغل الحرارة إلى ساعتين للوصول إلى عمق 10سم، وبإمكان الحرارة الوصول حتى العمق 20سم، وهذا يحدث خلال ساعات النهار حيث يبلغ أقصى مدى له قبل فترة الظهيرة ويستمر حتى فترة المساء، وبالتحديد يحدث ذلك بين الساعة 1000 والساعة 1800 ليصل إلى عمق 20سم، ويتدرج في الشدة حتى يصل أقصى شدة له عند عمق 5سم خلال الفترة الواقعة بين الساعة 1200 والساعة 1500، عندما تبلغ درجة حرارة سطح التربة قيمتها القصوى، وتحتاج عملية تغلغل البرودة إلى قرابة ثلاثة ساعات للوصول إلى عمق 5سم، وبإمكان البرودة التغلغل حتى عمق 10سم عندما تنخفض درجة حرارة سطح التربة إلى أدنى قيمة لها، وهذا يحدث خلال فترة بعد منتصف الليل ويستمر حتى ساعات الصباح الباكر وبالتحديد بين الساعة 0000 والساعة 0700 ليصل إلى عمق 10سم، ومن الساعة 0300 إلى الساعة 0600 حتى يصل إلى عمق 5 سم وهي فترة تمثل أعلى شدة تصل لها برودة التربة على عمق 5سم.

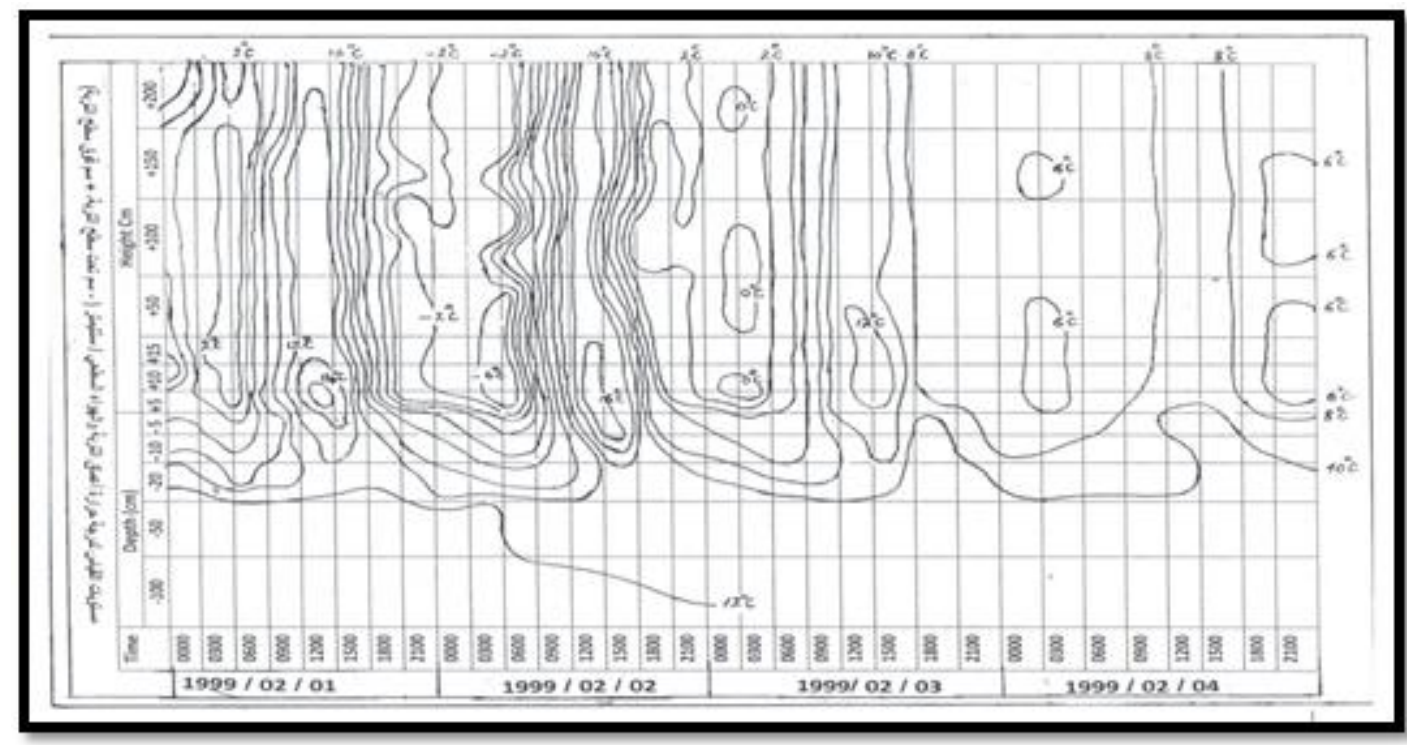

الشكل (1) المقطع الرأسي للتذبذب الحراري اليومي للتربة، (المصدر: الباحث)

2.1

درجة الحرارة السطحية اليومية هي محصلة ما يكسبه سطح الأرض والهواء الملاصق له من الأشعة الحرارية الشمسية وما يفقده منها بالإشعاع إلى الطبقات الجوية الأعلى على امتداد ساعات اليوم، وأنه بمقتضى هذا المسار تسجل النهايات العظمى لدرجة الحرارة عادة بعد منتصف النهار بحوالي ساعتين، بينما تسجل النهايات الصغرى قبل شروق الشمس، وهكذا فإن اضطراب المنحنى الحراري اليومي وتعرجه خلال اليوم الواحد يظهر أن درجة الحرارة تتذبذب خلال اليوم الواحد بمقدار قد يزيد عن خمس درجات خلال ساعة واحدة أو ساعتين، وترجع هذه التقلبات إلى أسباب متنوعة، ولكن أغلبها يحدث 152

http://www.misuratau.edu.ly/journal/jmuas/

المجلد الأول العدد الأول ديسمبر 2019 
نتيجة لتغير عنصر واحد أو أكثر من عناصر الطقس الأخرى، التي لها علاقة مباشرة بدرجة الحرارة، ومن أهمها ابتاه الرياح، ووصول جبهات هوائية لها صفات خاصة، وتكاثر السحب، وهطول الأمطار، أو تغير في قوة الإشعاع الشمسي، ويعتبر صفاء الجو في حد ذاته عاملا مهما من العوامل التي تتحكم في المسار الحراري اليومي لأنه يساعد على سرعة فقدان سطح التربة لحرارته بالإشعاع خلال فترة الليل فيؤدي إلى خفض النهاية الحرارية الصغرى بينما يساعد أثناء النهار على زيادة تأثير الأشعة وبالتالي يؤدي إلى ارتفاع النهاية العظمى، وفي هذه الحالة يكون المدى الحراري اليومي كبيرا

(Bouyoucos, 1913)

\section{1 التذبذب الحراري مع أعماق التربة والزمن في منطقة الدراسة:}

تتباين درجة الحرارة بين أعماق التربة في منطقة الدراسة وحسب زمن الرصد، حيث الخفضت درجة حرارة التربة إلى أدنى مستوياتما على عمق 5سم تحت سطح التربة خلال أيام الدراسة الخمسة عند الساعة 0600 صباحا، في حين ارتفعت درجة حرارة التربة إلى أعلى قيمة لها عند الساعة 1500 بعد الظهر، حيث تراوح المدى الحراري اليومي بين 13.2 م، خلال اليوم الثاني، و4.4 م، خلال اليوم الرابع (الشكل 2)، ويمكن تفصيل التباين في باقي الأعماق على النحو التالي: • العمق 10 سم: عند الساعة 0600 صباحا انخفضت درجة حرارة التربة إلى أدنى قيمة لما، وكان ذلك عند الساعة 0600 صباحا، وفي بعض الأحيان كان عند الساعة 0300 صباحا، بينما ارتفعت درجة حرارة التربة إلى أعلى قيمة لها عند الساعة 1500 بعد الظهر، تراوح المدى الحراري اليومي بين 11.3 مه، خلال اليوم الثاني، و 2.6 مº، خلال اليوم

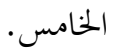

• العمق 20 سم : عند الساعة 0900 صباحا انخفضت درجة حرارة التربة إلى أدنى قيمة لها، بينما ارتفعت درجة حرارة التربة إلى أعلى قيمة لها عند الساعة 1800 بعد الظهر، تراوح المدى الحراري اليومي بين 4.5 م، خلال اليوم الثاني، و1.5 م، خلال اليوم الرابع واليوم الخامس.

• العمق 50 سم : عند الساعة 1800 مساء انخفضت درجة حرارة التربة إلى أدنى قيمة لها، بينما ارتفعت درجة حرارة التربة إلى أعلى قيمة لما عند الساعة 0000 صباحا، وكان المدى الحراري صغيرا حيث تراوح بين 1.2 م، خلال اليوم

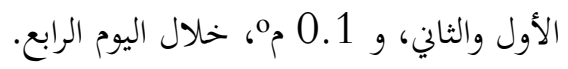

ـ العمق 100 سم : عند الساعة 2100 مساء انخفضت درجة حرارة التربة إلى أدنى قيمة لما، بينما ارتفعت درجة حرارة التربة إلى أعلى قيمة لما عند الساعة 0000 صباحا، وكان المدى الحراري صغيرا جدا حيث تراوح بين 0.8 م، خلال اليوم الأول والثاني، و 0.0 م.0، خلال اليوم الرابع.

والخلاصة: أن حرارة الطبقة الأولى التي تبدأ من السطح حتى عمق 20سم، تتسم بنمط يتلاءم مع نمط حرارة الهواء حيث تحدث النهايات الصغرى لدرجة الحرارة أثناء الليل بينما تحدث النهايات العظمى لدرجة الحرارة أثناء النهار، أما الطبقة الثانية 153 
التي تبدأ بعمق أكبر من 20 سم وتمتد حتى عمق 100 سم فإنها تتسم بنمط معاكس للطبقة الأولى حيث تحدث النهايات الصغرى لدرجة الحرارة أثناء النهار بينما تحدث النهايات العظمى لدرجة الحرارة أثناء الليل، ويقل المدى الحراري كلما زاد العمق داخل التربة، وكلما زاد العمق داخل التربة تكون درجة الحرارة أعلى من الأعماق التي فوقها وبالإمكان

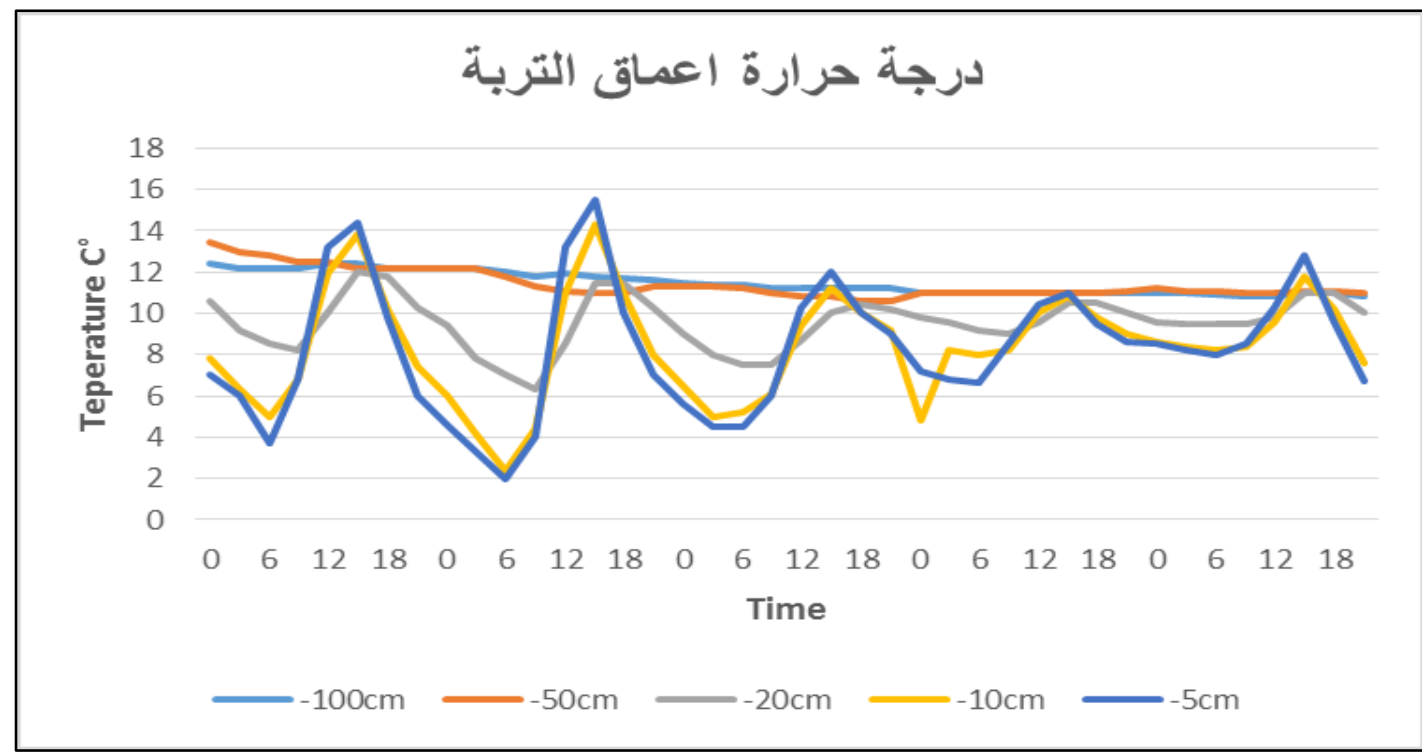

الشكل (2) التبذب الحراري اليومي لأعماق التربة، (المصدر: الباحث)

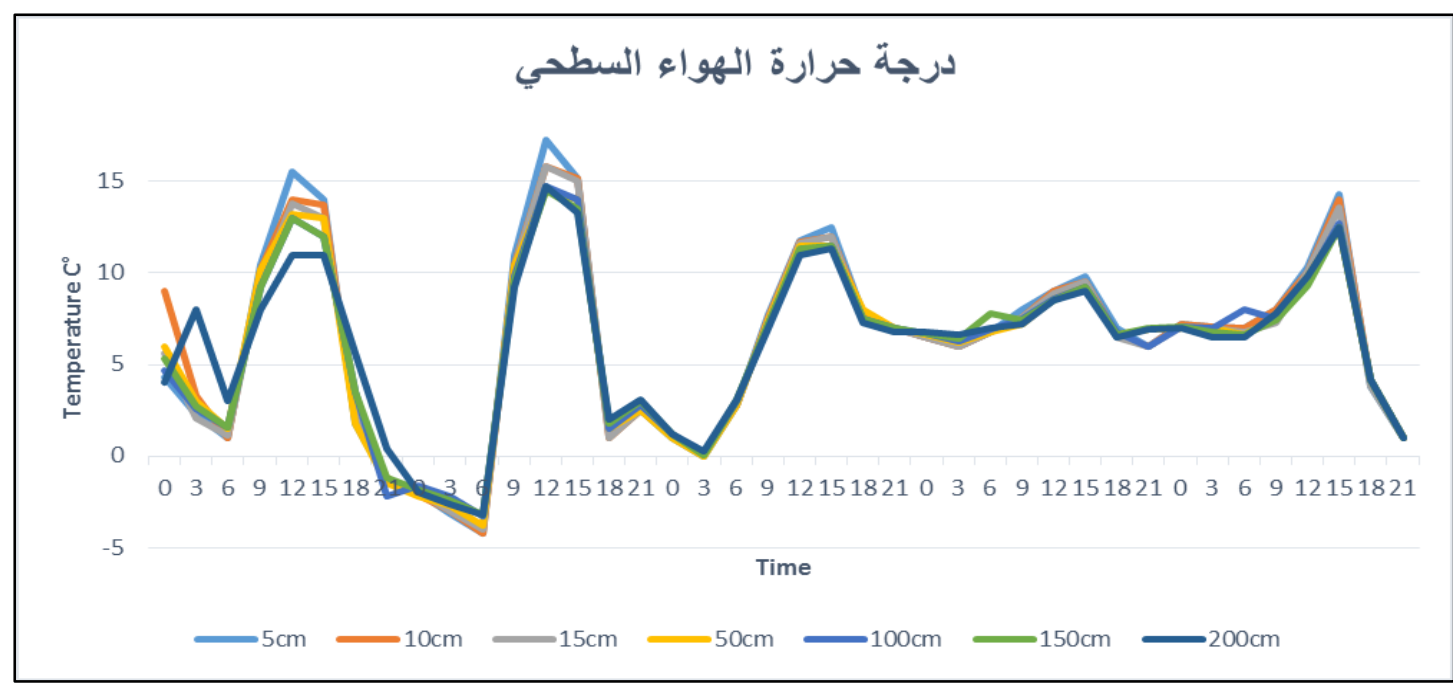

الشكل (3) التذبذب الحراري اليومي للهواء السطحي، (المصدر الباحث) 
ملاحظة ذلك من خلال النظر إلى المنحنيات التي تمثل درجة حرارة العمق 50سم والعمق 100سم، باستثناء فترات الظهيرة التي يبلغ فيها تأثير الإشعاع الشمسي ذروته، ومن الشكل (3) نلاحظ التناغم بين إيقاع التذبذب الحراري اليومي للهواء السطحي على كافة المستويات وهذا يدل على بتحانس الطبقة السطحية للهواء الجوي، نظرا للتماثل في شدة العوامل المؤثرة عليها. ويبين الشكل (4) أن درجة حرارة أعماق التربة تتأثر بدرجة حرارة الهواء الذي يعلوها مباشرة، ويكون التأثير قويا على الأعماق العلوية القريبة من السطح ثم يقل تدريجيا كلما زاد العمق إلى أن يختفي عند العمق 50سم والعمق 100سم، ويرجع ذلك إلى تأثر التربة ببرودة الهواء الملاصق لها إضافة إلى تأثرها بالإشعاع الشمسي، كما يتضح أيضا وجود إيقاع متبادل بين انخفاض درجات حرارة التربة والهواء خلال الفترة الواقعة بين الساعة 0300 والساعة 0600 وارتفاعها خلال الفترة الواقعة بين الساعة 1200 والساعة 1500، مع وجود اختلاف في سعة التذبذب بين حرارة التربة وحرارة الهواء.

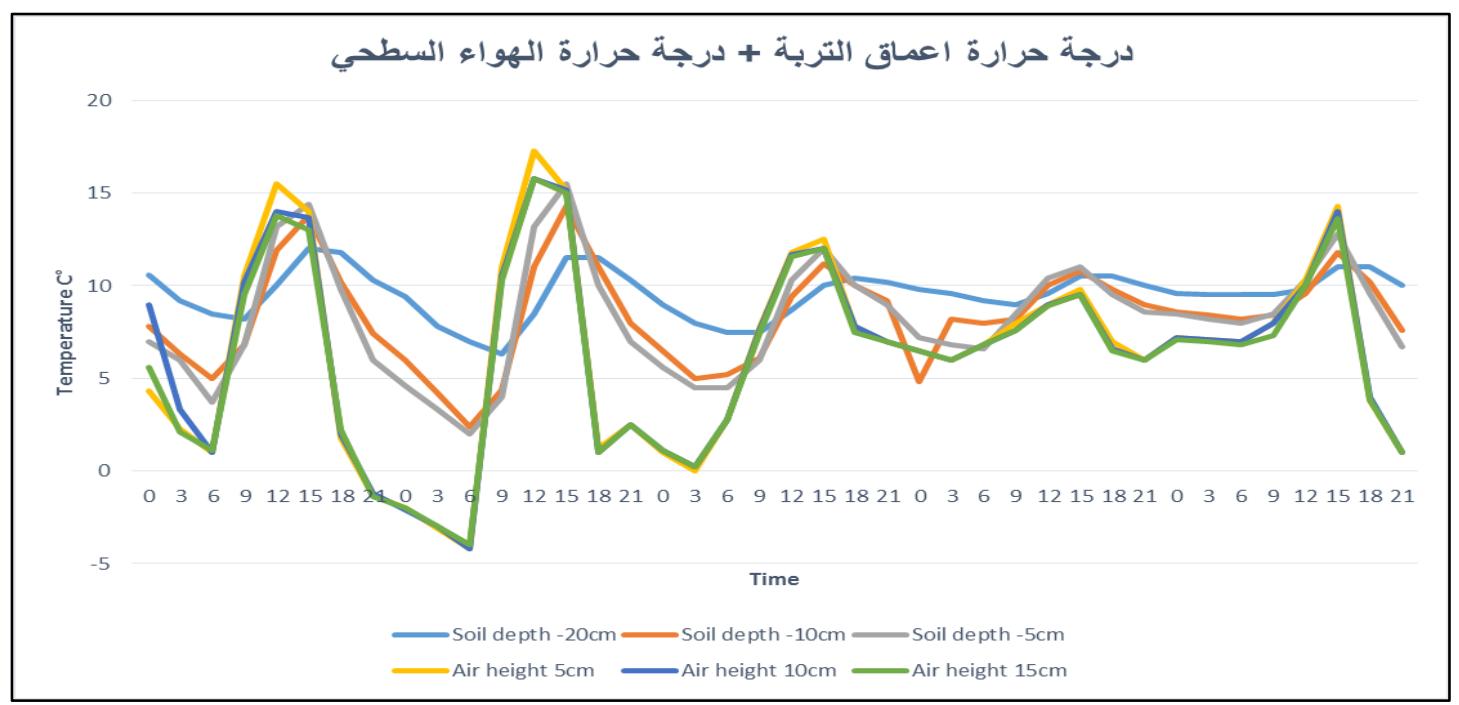

الشكل 4 : التذبذب الحراري اليومي للتربة السطحية والهواء السطحي، (المصدر : الباحث)

\section{1 - التردد الموجي اليومي لدرجة حرارة الهواء ودرجة حرارة التربة:}

لتوضيح نمط تردد الموجة الحرارية المؤثرة (حرارة الهواء السطحي)، وتردد الموجة الحرارية المنتقلة (حرارة التربة السطحية)، تم التركيز على نمط التذبذب الحراري اليومي بين درجة الحرارة القصوى ودرجة الحرارة الصغرى للهواء السطحي والتربة السطحية، وبناء على التحاليل التي تم إجراؤها على البيانات اتضح أن التذبذب اليومي لدرجة حرارة التربة ضمن الأعماق المقاسة يتأثر بدرجة حرارة الهواء السطحي ويكون التأثير واضحا بالأعماق القريبة من السطح ويقل التأثير بزيادة العمق، أي أن تذبذب درجة حرارة الهواء خلال اليوم ستظهر بصورة أقل عند العمق 50سم مقارنة بالأعماق 5 و 10 و20سم، وتكون بصورة 
أقل جدا عند العمق 100سم، وأن معامل التأخير الحراري عند المقارنة بين أقصى تذبذب في درجة حرارة الهواء وأقصى تذبذب في درجة حرارة التربة عند العمق 50سم تقريبا ستكون في حدود ساعتين ويكون معامل التأخير الحراري أقل من ساعتين للأعماق القريبة من سطح التربة، وللتوضيح تم تصميم ورسم الشكل رقم (5)، الذي يبين العلاقة بين تردد الموجة الحرارية المؤثرة (حرارة الهواء السطحي)، وتردد الموجة الحرارية المنتقلة (حرارة التربة السطحية)، وذلك بناء على القيم الواردة في الجلدول (3)، والجدول (4)،تم جمع قيمة متوسط (tt )، لدرجات حرارة الهواء المسجلة عند الارتفاعات 5 و10سم ta = وقسمة حاصل الجمع على 2 بحيث يعبر ناتج القسمة على قيمة تردد الموجة الحرارية للهواء السطحي 13.11 (هoc) و وبنفس الطريقة تم تطبيق ذلك على درجات الحرارة المسجلة عند أعماق التربة 5سم و10سم، وبناء عليه كانت

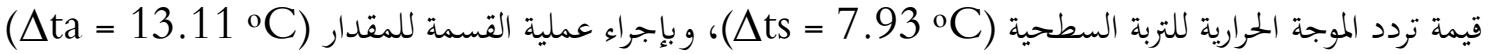

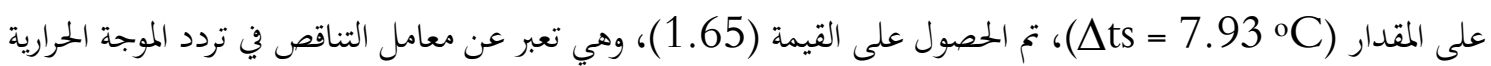
بين الهواء السطحي والتربة السطحية.

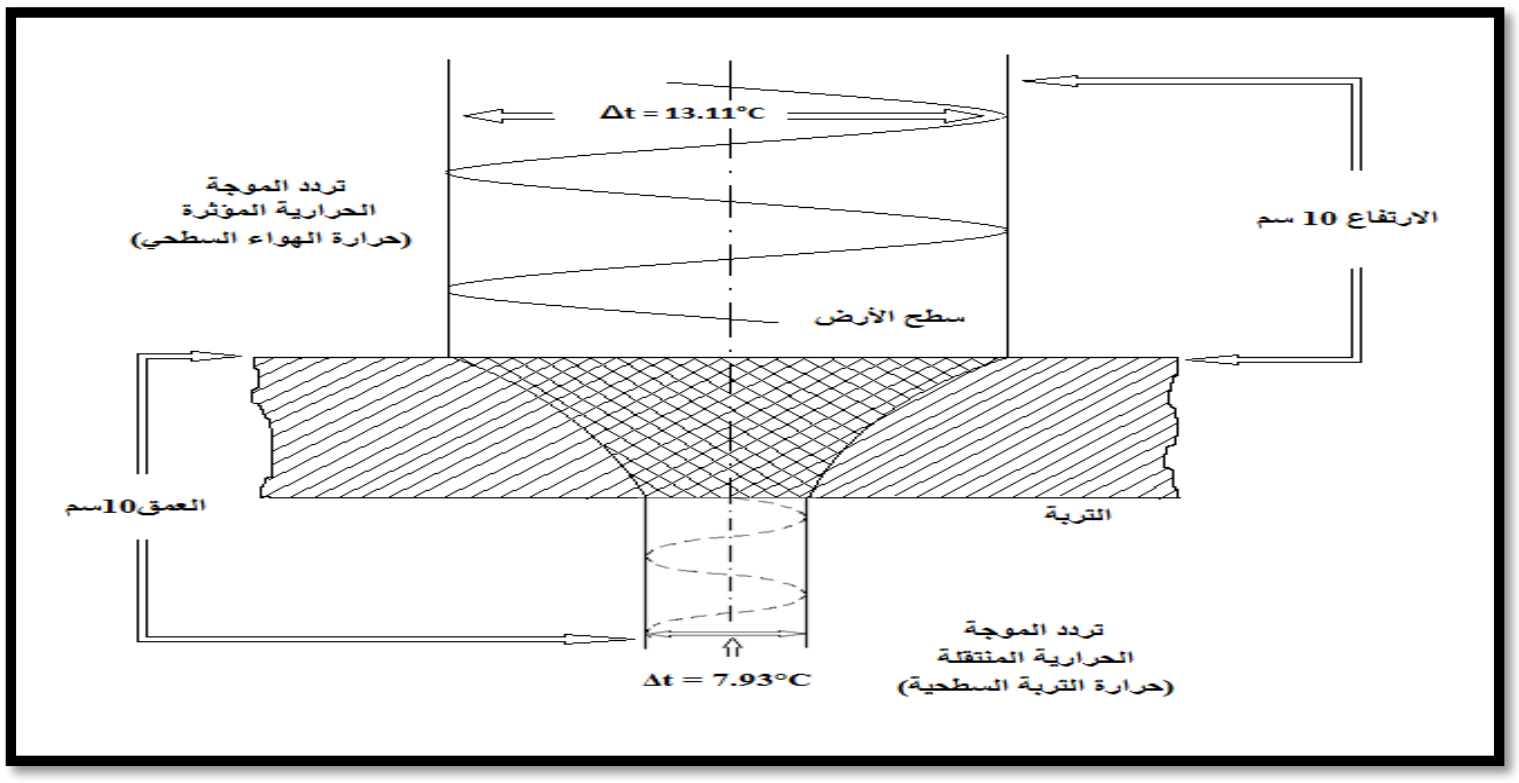

الشكل(5) التردد الموجي اليومي لدرجة حرارة المواء السطحي ودرجة حرارة التربة السطحية، (المصدر: الباحث)

2

الجدول (3) والجدول (4) يلخصان المدى الحراري لأعماق التربة 10 و5سم، والمدى الحراري للهواء الجوي عند الارتفاعات 5 و10سم، ومن الجداول نلاحظ أن المدى الحراري للتربة كان أقل من المدى الحراري للهواء، حيث كان متوسط المدى الحراري للعمق 5سم تحت سطح التربة 8.44 م، و 7.42 م م للعمق 10سم، بينما كان متوسط المدى الحراري للارتفاع 5سم فوق سطح التربة 13.58 م و 12.64 م نلارتفاع 10سم، ونلاحظ أيضا أنه خلال الطبقة المحصورة بين العمق 156 
10سم تحت سطح التربة والارتفاع 10سم فوق سطح التربة أن المدى الحراري يبلغ قيمته القصوى بالقرب من السطح ثم ينخفض كلما زاد العمق داخل التربة وينخفض أيضا كلما زاد الارتفاع إلى أعلى، وهذا يرجع إلى تأثير الإشعاع الشمسي على سطع التربة حيث تقوم التربة بامتصاص جزء منه وتعمل على انعكاس الجزء الآخر.

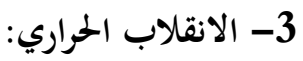

تتميز درجة حرارة طبقة الهواء الجوي القريبة من سطح التربة بالانخفاض كلما زاد الارتفاع إلى أعلى، والسبب في ذلك أن هذه الطبقة تستمد حرارها من أشعة الشمس المنعكسة من الأرض، فعندما تصل أشعة الشمس إلى الأرض، تمتص الأرض جزءًا من هذه الأشعة، والجزء الآخر ينعكس إلى أعلى، لذلك ترتفع درجة حرارة طبقة المواء الملامسة لسطح الأرض، وكلما ابتعدنا عن سطح الأرض تنخفض درجة الحرارة، في هذه الطبقة تحدث جميع التغيرات في حالة الطقس .Oke, T. ( R., 1987) ،حدث أحيانًا في طبقة الهواء الجوي القريبة من سطح التربة وضع معكوس، حيث ترتفع درجة الحرارة مع الارتفاع، يدعى هذا الوضع انقلاب حراري، هذا الوضع يكون فيه الهواء البارد موجودا في الأسفل وفوقه يوجد هواء حار، الانقلاب الحراري هو وضع متطرف يساعد في تلويث الغلاف الجوي، وهو ضار جدا بالمزروعات نتيجة تسببه في برودة (Kurian, J., and others, سطح الأرض بالليل، وهذا الوضع سائد جلًا في الليالي الصافية والرياح الحفيفة

الجدول (3) المدى الحراري لعمق التربة 5 سم والملدى الحراري للهواء الجوي عند الارتفاع 5 سم.

\begin{tabular}{|c|c|c|c|c|c|c|}
\hline \multicolumn{3}{|c|}{ المدى الحراري للهواء } & \multicolumn{3}{|c|}{ المدىى الحراري للتربة } & \multirow{3}{*}{ 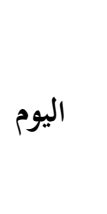 } \\
\hline \multicolumn{3}{|c|}{ الارتفاع 5 سم } & \multicolumn{3}{|c|}{ العمق 5 سم } & \\
\hline$\Delta \mathbf{T}$ & حرارة عظمى & حرارة صغرى & $\Delta \mathbf{T}$ & حرارة عظمى & حرارة صغرى & \\
\hline${ }^{\circ}, 16.8$ & o 15.5 & o $1.3-$ & o 10.7 & o 14.4 & ${ }^{\circ}, 3.7$ & الأول \\
\hline${ }^{\circ}, 21.5$ & $o_{\beta} 17.3$ & ${ }^{\circ}, 4.2-$ & o, 13.5 & o 15.5 & ${ }^{\circ}, 2.0$ & الثاني \\
\hline 12.5 & 12.5 & ${ }^{\circ}{ }_{\beta} 0.0$ & ${ }^{\circ}, 7.5$ & ${ }^{\circ}, 12.0$ & ${ }^{\circ}, 4.5$ & الثالث \\
\hline${ }^{\circ}, 3.8$ & ${ }^{\circ}, 3.8$ & ${ }^{\circ}, 6.0$ & ${ }^{\circ}, 4.4$ & ${ }^{\circ}{ }_{p} 11.0$ & ${ }^{\circ}, 6.6$ & الرابع \\
\hline o 13.3 & o 13.3 & ${ }^{\circ}, 1.0$ & $0,6.1$ & 12.8 & ${ }^{\circ}, 6.7$ & الخامس \\
\hline${ }^{\circ}{ }^{\circ} 13.58$ & 13.88 & ${ }^{\circ}, 0.3$ & 号 8.44 & ${ }^{\circ}$ p 13.14 & ${ }^{\circ}, 4.7$ & المتوسط \\
\hline
\end{tabular}

المصدر: الباحث

إذا بدأ الانقلاب الحراري بداية من سطح الأرض فهو يدعى انقلابا حراريا أرضيا، يحدث الانقلاب الحراري الأرضي (الانقلاب الإشعاعي)، في الليالي الباردة ذات السماء الصافية والرياح الهادئة في المناطق المعتدلة والباردة، فصفاء السماء 
يجعل جزءاً كبيراً من الإشعاع الأرضي يتسرب إلى الفضاء، كما أن هدوء الرياح يسمح للهواء بالبقاء ملامساً لسطح الأرض ساعات طويلة تكفي لانخفاض درجة حرارته بحيث يصبح الهواء الواقع فوقه أدفأ منه، ويساعد طول الليل وقصر النهار أثناء فصل الشتاء على حدوث هذا النوع من الانقلابات الحرارية، وبالتحديد يحدث هذا الانقلاب غالبا في ليالي الشتاء الطويلة، حيث تفقد الأرض حرارتا خلال الليل الطويل فيصبح الهواء الملاصق لسطح الأرض أكثر برودة من المواء الموجود فوقه مباشرة، ويتبدد هذا الانقلاب بعد شروق الشمس بقليل، (Thadathil, et al.,1992) ، يشكل هذا النوع من الانقلاب خطورة على المزروعات حيث قد تقتل طبقة الهواء الباردة بعض المزروعات خاصة الخضروات، كما تؤدي إلى الإضرار بالفواكه مثل الحمضيات فتؤدي إلى تجفيف الماء في داخلها، إنّ برودة سطح الأرض يحدث كالآتي: تطلق الأرض الطاقة الحرارية التي استوعبتها خلال ساعات النهار بواسطة الإشعاع إلى المواء الذي فوقها، ولذلك يبرد سطح الأرض ويؤدي إلى تبريد المواء الملامس له، وهذا ما حدث خلال فترة الدراسة حيث كانت السماء غالبا خالية من السحب مع وجود بعض السحب القليلة العابرة محدودة التأثير، والرياح كانت ساكنة إلى خفيفة السرعة، بعد شروق الشمس تبدأ الأرض بالدفء، وتدفئ الهواء من فوقها وبعد عدة ساعات يختفي الانقلاب الحراري، إن حدوث الانقلاب الحراري خلال ساعات الصباح يزيد من شدة تأثيرها السلبي على المزروعات خاصة في فاية فصل الخريف وفي فصل الشتاء، عندما تكون حالة الطقس مستقرة والرياح ضعيفة، في الليالي الطويلة من هذه الفصول تبرد الأرض بشكل كبير ويحدث انقلاب حراري سميك لذلك تنقشع (تتهدم) حالات الانقلاب الحراري بعد وقت طويل من شروق الشمس (Thadathil, et al., 2016)

\section{الجددول (4) المدى الحراري لعمق التربة 10 سم والمدى الحراري للهواء الجوي عند الارتفاع 10سم.}

\begin{tabular}{|c|c|c|c|c|c|c|}
\hline \multicolumn{3}{|c|}{ المدىى الحراري للهواء } & \multicolumn{3}{|c|}{ المدى الحراري للتربة } & \multirow[b]{3}{*}{ 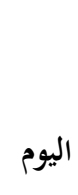 } \\
\hline \multicolumn{3}{|c|}{ الارتفاع 10 سم } & \multicolumn{3}{|c|}{ العمق 10 سم } & \\
\hline$\Delta \mathrm{T}$ & حرارة عظمى & حرارة صغرى & $\Delta \mathrm{T}$ & حرارة عظمى & حرارة صغرى & \\
\hline${ }^{\circ}{ }^{\circ} 15.2$ & ${ }^{\circ}{ }^{\circ} 14.0$ & ${ }^{\circ}{ }^{\circ} 1.2-$ & ${ }^{\circ} 8.8$ & o 13.8 & ${ }^{\circ}$ p 5.0 & الأول \\
\hline${ }^{\circ}{ }^{\circ} 20.0$ & 15.8 & ${ }^{\circ} 4.2-$ & o 11.9 & 14.3 & ${ }^{\circ}{ }^{\circ} 2.4$ & الثاني \\
\hline 11.8 & 12.0 & 0.2 & 6.2 & 11.2 & ${ }^{\circ}, 5.0$ & 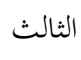 \\
\hline${ }^{\circ}, 3.2$ & ${ }^{\circ}, 9.2$ & ${ }^{\circ}, 6.0$ & ${ }^{\circ}$; 6.0 & o 10.8 & ${ }^{\circ}, 4.8$ & الرابع \\
\hline${ }^{\circ}{ }^{\circ} 13.0$ & ${ }^{\circ}, 14.0$ & ${ }^{\circ}, 0 . \&$ & ${ }^{\circ}, 4.2$ & 11.8 & ${ }^{\circ}, 7.6$ & الخامس \\
\hline o 12.64 & ${ }^{\circ}, 13.0$ & ${ }^{\circ} 0.36$ & ${ }^{\circ}, 7.42$ & 12.38 & ${ }^{\circ}, 4.96$ & لمتوسط \\
\hline
\end{tabular}

المصدر: الباحث 
عدد خاص بالأوراق العلمية المقدمة للمؤتمر العلمي الأول للعلوم الزراعية ــ إنتاج نباتي (5-6 أكتوبر 2019)

من الجدول (5)، نلاحظ تكون حالة انقلاب حراري تكونت خلال ساعات الليل والصباح الباكر، وذلك بسبب أن عملية فقدان التربة لحرارتا بواسطة الإشعاع بلغت ذروتا وهذا يساعد في انخفاض درجة حرارة التربة والهواء الملاصق لها، بينما نلاحظ العكس خلال ساعات النهار حيث تنخفض درجة الحرارة بالارتفاع إلى أعلى وهذا يتوافق مع الحالة العامة.

الجمدول (5) المقطع الرأسي لدرجة حرارة الهواء خلال يوم 1999/02/02

\begin{tabular}{|c|c|c|}
\hline درجة الحرارة المسجلة عند الساعة 12:00 ظهرا & درجة الحرارة المسجلة عند الساعة 06:00 صباحا & مستوى القياس فوق سطح التربة \\
\hline${ }^{\circ}{ }^{\circ} 14.7$ & 足 3.2 - & 200 سم \\
\hline 14.5 & ${ }^{\circ}, 3.2$ & (150 سم \\
\hline o 14.7 & ${ }^{\circ}, 3.3$ & 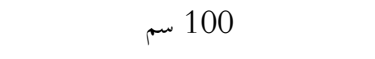 \\
\hline o 14.5 & ${ }^{\circ}, 3.8$ & 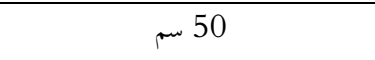 \\
\hline o 15.8 & ${ }^{\circ}, 4.0$ & 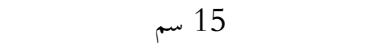 \\
\hline o l 15.8 & ${ }^{\circ}, 4.2$ & 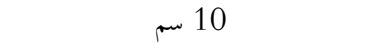 \\
\hline o 17.7 & ${ }^{\circ}, 4.2 \quad-$ & 5 سم \\
\hline
\end{tabular}

المصدر: الباحث

أنواع الصقيع:

يعرف الصقيع Chilling بأنه انخفاض درجة حرارة التربة أو الهواء المحيط بالنبات إلى ما دون درجة الصفر المئوي حيث يبدأ حدوث بحمد المياه في خلايا النبات ما يؤثر على نشاطه وحياته،(Lukatkin, et al., 2012) ، يصنف الصقيع حسب طبيعة تشكله وزمن حدوثه والأضرار التي يسببها للنبات إلى نوعين هما: الصقيع المتحرك والصقيع الإشعاعي، يحدث الصقيع المتحرك عندما تتقدم كتلة هوائية باردة أو جبهة باردة على منطقة ما فينخفض معدل الحرارة اليومي، كما يقل المدى الحراري اليومي وبسبب تجدد الهواء البارد باستمرار وتصعب مقاومة الصقيع المتحرك، (DaminiThawait, 2104)، ومن حسن الحظ أن هذا النوع من الصقيع يحدث غالباً في الشتاء عندما تكون الأشجار المثمرة في طور السكون وتتحمل درجات حرارة منخفضة، في حالات الصقيع الإشعاعي تكون حرارة الهواء الملامس لسطح التربة أخفض من حرارة المواء على ارتفاع مترين، وهذا ما حدث خلال فترة الدراسة الحالية حيث الخفضت درجة حرارة الهواء عند السطح إلى 4.2 درجة مئوية تحت الصفر خلال يوم 02 فبراير بينما كانت على ارتفاع 200 سم 3.2 درجة مئوية تحت الصفر وكانت الرياح ساكنة إلى خفيفة السرعة أحيانا، وغالباً ما يحدث هذا النوع من الصقيع أثناء فصل الربيع، لذلك يسمى بالصقيع الربيعي، والصقيع الربيعي أشد خطراً من الصقيع الشتوي بسبب حدوثه في فترة النمو، ويترافق موعد حدوث الصقيع الربيعي مع طور الأزهار للأشجار المثمرة، ويتعلق حدوث الصقيع وشدته بعوامل عدة أهمها: أ - خلو السماء من السحب: تزداد شدة الصقيع عندما تكون السماء صافية خالية من السحب لأن السحب تحد من شدة الصقيع حسب كميتها ونوعها. 159 
ب - الرطوبة : يؤثر بخار الماء الموجود في التربة والهواء في الحد من الانخفاض المفاجئ لدرجة حرارة الهواء أو التربة فعندما يتجمد بخار الماء يطلق قدراً من الحرارة تقلل من حدة الصقيع وأحياناً تحول دون حدوثه كما أن بخار الماء الموجود في الجو يجفظ حرارة الأرض ليلاً إذ يقلل من إشعاع الأرض ويزداد هذا الأثر كلما زاد بخار الماء في الجو. ج - سرعة الرياح : تزيد سرعة الريح من عملية الخلط الميكانيكية للهواء بين الطبقات الباردة الملامسة للسطح أثناء حدوث الصقيع الإشعاعي وبين الطبقات الأدفأ التي تعلوها وبالتالي تقلل الرياح من خطر الصقيع الإشعاعي، ويحدث العكس في حالة الصقيع المتحرك إذ تزيد الرياح من أضرار الصقيع المتحرك. د - حالة الأرض الفيزيائية والغطاء النباتي : إن حراثة الأرض وتقليبها يؤدي إلى زيادة المسامات في التربة ما يقلل من ناقليتها للحرارة من الطبقات العميقة إلى الطبقات السطحية، (Veronica, et al., 2015) ، لذلك ينصح بعدم حراثة الأرض المعرضة للصقيع إلا بعد زوال خطر وقوعه، كما أثبتت بعض التجارب التي أجريت في بريطانيا بأن طبقات المواء فوق الأرض العشبية أكثر برودة من طبقات الهواء فوق الأرض العارية لذلك ينصح بقص الأعشاب تحت الأشجار المثمرة أثناء فصل الربيع للتقليل من خطر وقوع الصقيع على مستوى البراعم، (Bollero, et al., 1996) ، من حسن الحظ أن الصقيع يحدث غالباً في الشتاء عندما تكون الأشجار المثمرة في طور السكون وتتحمل درجات حرارة منخفضة، إلا إن النباتات تتأثر بالصقيع في فترة النمو كما تتضرر من الصقيع الشتوي في طور السكون وأعضاء النبات المعرضة للصقيع الشتوي هي الجذور وعقدة الطعم وأسفل الساق وتفرعاته والبراعم الخشبية والزهرية، (Kaspar, et al., 1992) ، إذ يسبب الصقيع تخريب البراعم الخشبية والزهرية والأنسجة النسغية وخاصة في الفروع الحديثة، وتكون قاعدة الساق من الأجزاء الأكثر تضرراً بسبب بتمع الهواء البارد بالقرب من سطح التربة، وكذلك قمة الأغصان؛ بسبب شدة ضياع الحرارة بالإشعاع ويظهر أثر الصقيع على النباتات خلال الأسابيع الأولى من فترة النمو، ويسبب الصقيع تعفن البراعم وسقوط الأزهار، كما

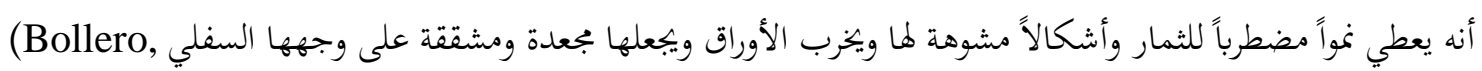
(et al., 1996) ويقلل الصقيع من قدرة النبات على الامتصاص، كما أشارت بعض الأبحاث إلى إن انخفاض درجة حرارة التربة قد يسبب نقصا واضحا في امتصاص الماء منها فيحصل ذبول للنبات، وهذا ما يطلق عليه بالذبول الفسيولوجي، وهي عدم قدرة النبات على امتصاص الماء من التربة رغم تواجده فيها، (Hanks, 1992). ويسبب الخفاض درجة الحرارة زيادة في لزوجة البروتوبلازم في خلايا الجذور وهذا له تأثير على انتشار الماء من التربة إلى خلايا الجذور، ولهذا السبب الجذور المتجمدة لا ينتقل الماء فيها ولا يمكن للمحاصيل الحقلية أن تعطي أفضل إنتاج لها في درجة حرارة ثابتة خلال فصل نموها، بل تحتاج إلى درجات حرارة معينة خلال كل طور من أطوار حياتا، (Kaspar, et al., 1992).

\section{طرق الوقاية من الصقيع ومقاومته، طرق الوقاية السلبية:} تجنب تأخير موعد الزراعة بعد 15 ديسمبر، فذلك يؤدي إلى تعرض البذور لانخفاض درجات الحرارة وبالتالي فإن الإنبات 
قد يتأثر نتيجة تثبيط أنزيمات الإنبات تحت ظروف الحرارة المنخفضة كما أن الأوكسجين يقل أيضاً نتيجة انخفاض درجات الحرارة، ويؤدي الانخفاض أيضاً إلى تقصير طول السلامية وبطئ نموها وقد لا تستطيع البزوغ فتهلك في طريق النمو، إن تأخر نمو البذور فوق التربة عند الزراعة المتأخرة بعد 15 ديسمبر يعود إلى عدم قدرقا على بحميع الوحدات الحرارية اللازمة للإنبات والنمو، وبسبب الخفاض درجات الحرارة تتأخر البذور داخل التربة لمدة طويلة وربما تحلك الأجنة، وأن البذور التي نمت فوق سطح التربة سيكون نموها بطيئً؛ لأهما ستصادف الخفاض درجات الحرارة، وبذلك لا تأخذ البذور المدة الزمنية اللازمة لتحقيق طور خضري جيد، وبالتالي يتأثر الطور الخضري الذي يعتبر طوراً مهماً لتكوين خيمة نباتية مثالية وعدد تفرعات لتنشأ فيه مواقع الحبوب والأزهار والسنابل، وهنا بتحر الإشارة إلى أن التبكير بموعد الزراعة قبل 15 نوفمبر يؤدي إلى أن تصادف عملية نمو السنابل وتلقيح الزهيرات موجات البرودة خلال المدة من 15 يناير إلى 15 فبراير وربما يؤدي ذلك إلى فشل التلقيح أو الإخصاب إذ أن النخاض درجات الحرارة ربما يؤدي إلى قتل حبوب اللقاح أو حصول التلقيح لكن لا تتطور أنابيب التلقيح فيفشل الإخصاب وبالتالي لا تتكون حبوب أصلاً، فينخفض عدد الحبوب في السنبلة الواحدة فيقل المحصول، أو قد تتكون حبوب إلا أن معدلات نقل المادة الجافة إلى الحبوب تكون بطيئة وقليلة جدا بسبب انخفاض درجات الحرارة وبالتالي تتكون حبوب ضعيفة خفيفة الوزن فينخفض المصصول نتيجة انخفاض وزن الحبة

.(Lukatkin, et al., 2012)

\section{الخلاصة:}

يتسم تغير درجة حرارة التربة، بالتعاقب الدوري المنتظم، على المدى اليومي، بين الليل والنهار، وهذه الدورات اليومية لدرجة حرارة التربة، ليست على نمط ثابت تماماً؛ إنما يعتريها عدم الانتظام، الناجم عن ظواهر الطقس العرضية، غير المنتظمة، مثل: موجات البرد، وموجات الحر، تناولت هذه الدراسة إجراء دراسة حالة لتشخيص التذبذب اليومي في المقطع الرأسي لدرجات حرارة التربة والطبقة الحدية للهواء الجوي الملاصق لسطح التربة وذلك تحت تأثير موجة برد تعرضت لها منطقة شثمال غرب ترب ترسب ليبيا، استناداً إلى بيانات درجات الحرارة الساعيّة التي تم رصدها بواسطة محطة الزاوية للأرصاد الجوية الزراعية، بينت النتائج المبدئية أن درجة حرارة أعماق التربة تتأثر بدرجة حرارة الهواء الذي يعلوها، ويكون التأثر قويا على الأعماق القريبة من السطح ثم يقل تدريجيا كلما زاد العمق إلى أن يختفي عند العمق 100سم، ويرجع ذلك إلى تأثر التربة ببرودة الهواء الملاصق لها إضافة إلى تأثرها بالإشعاع الشمسي، كما دلت النتائج على وجود إيقاع متبادل بين انخفاض درجات حرارة التربة السطحية والهواء السطحي، وتم التعرف على شكل المدى الحراري للتربة والهواء خلال موجة البرد، توصلت الورقة إلى عدد من الاستنتاجات والتوصيات التي تبين أهمية القيام برصد وتحليل حرارة التربة خلال موجات الصقيع لأجل أخذ التدابير اللازمة للتقليل من آثارها الضارة على المحاصيل الزراعية. 


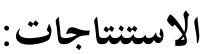

توصلت الدراسة إلى مجموعة من النتائج، يمكن تلخيصها على النحو التالي:

1. تتذبذب درجة الحرارة في طبقة المواء السفلية الملاصقة لسطح التربة ليلاً وهماراً وفق نظام معقد خاص إذ يلاحظ في ساعات الليل المتأخرة وخاصة في ليالي الصقيع الإشعاعي أن درجة الحرارة تزداد مع الارتفاع حتى بضعة أمتار ثم تعود فتنخفض ثانية مع الارتفاع، وذلك بسبب البرودة المتسارعة لسطح الأرض نتيجة فقدها للحرارة بواسطة الإشعاع الأرضي ونتيجة للنوا السماء من السحب وضعف حركة الرياح. 2 يوجد نوعان من التذبذبات في درجات حرارة أعماق التربة، الأول يمثل التذبذب الذي يحدث في الطبقة السطحية القريبة من سطح التربة وهو تذبذب قوي يمتد حتى العمق 20سم أو أكثر بقليل، التذبذب الثاني وهو تذبذب ضعيف يقل كلما

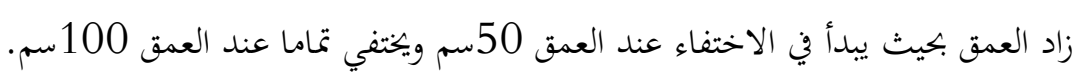

3 يوجد اختلاف بين نمط التردد الموجي اليومي لحرارة المواء والتربة وذلك يرجع إلى مدى الاختلاف بين درجة التأثر بالعوامل البيئية كالإشعاع والرياح والرطوبة، تتذبذب درجات حرارة أعماق التربة بصورة أبطأ بكثير من درجة حرارة الهواء الجوي

السطحي.

4. تكمن أهمية درجة حرارة التربة في تأثيرها على العمليات الزراعية خاصة أثناء مرحلة الإنبات أو نمو البذور. 5. يتسبب الصقيع في إلحاق الضرر بمكونات النبات خاصة الفروع الحديثة الطرية وتكون قاعدة الساق من أجزاء النبات الأكثر تضرراً بسبب بتمع الهواء البارد بالقرب من سطح التربة.

التوصيات:

توصي الدراسة بمجموعة من التوصيات المهمة، منها:

1. إجراء الدراسات التحليلية والتطبيقية حول موجات البرد والصقيع التي تتأثر بها المناطق الزراعية في ليبيا. 2. دراسة تأثيرات الانغفاض الحاد في درجة حرارة الهواء والتربة على حبوب اللقاح وعمليات التلقيح والإخصاب النباتي. 3 الاهتمام بإنشاء محطات الرصد والقياس والتسجيل المستمر لدرجة حرارة أعماق التربة بكافة المناطق الزراعية. 4. تحديد الإجراءات والتدابير التي تساعد على الوقاية من البرد والصقيع والتقليل من شدة تأثيره على الحقول الزراعية. 5. انتقاء أنواع البذور والشتول وذلك بالتركيز على الأصناف متأخرة الإزهار والأقل تضرراً بموجات البرد والصقيع. 6. القيام بالتدابير التي تسهل تصريف الهواء البارد من الحقول والبساتين. 7. قص الأعشاب تحت الأشجار المثمرة وتسوية الأرض بعد الحراثة لتسهيل انتقال الحرارة من طبقات التربة العميقة وتقليم الأشجار وترك مسافة بين تاج الشجرة وسطح الأرض قدر الإمكان. 
Al Rawi S. M., (1990) : Soil Temperature in determining the Ideal period for wheat seed germination in Iraq, Iraq Geography Journal Vol. 24. pp 221.

Ali, A. A., and others (1989) : The effect of varying temperature on germination of some seeding, wheat and barley seeding Zanko Salahuddin Magazine, volume 2, First Issue, Higher Education Press.

Al-Ani A. N. (1988) : Soil Relationship with Water and its effect on irrigation period and Quantity of irrigation water added, College of Agriculture, University of Baghdad, pp 95.

Bollero, G. A., D. G. Bulluck, and S. E. Hollinger, (1996) : Soil temperature and planting date effects on corn yield, leaf area, and plant development. Agron. Journal., 88, 385-390.

Bouyoucos G. J., (1913) : An investigation of Soil temperature and some of the most important factors influencing it. Michigan Agricultural Experimental Station Technical Bulletin, 17, 7-196.

Damini Thawait (2104) : Chilling Stress and its effect in Plants, Dep. Of Agronomy.

El-hjaji, S. A., (1989) : New Libya, 3ed Edition, Published by Elfteh Center, pp., 40-48.

Farouki, O. T., (1986) : Thermal properties of soil. Series on rock and soil mechanics. Vol. 11. Trans Tech Pub1., Clausthal-Zellerfeld, Germany.

Fisher, R.A. (1946) : Statistical methods for Research workers, p.209 tenth edition Edinburgh.

Gawad A. A., and others (1989) : Introduction to Crop Science, Fundamental of Production, Arab Publishing House, PP 71-72.

Hanks, R. J., (1992) : Applied Soil Physics: Soil Water and temperature Applications. Springer Verlag, New York.

Hilled, D., (1982) :Introductin to soil physics, Academic Press, San Diego, CA.

Hillel, D,.(1980) : Fundamental of Soil Physics. Academic Press, 413 pp.

Hillel, D., (1982) : Introduction to soil physics. Academic Press, San Diego, CA.

Islam K., Khan, A. and Islam T,. (2015) : Correlation between Atmospheric temperature and Soil temperature : A Case Study for Dhaka, Bangladesh, Atmospheric and Climate Sciences, 5, pp. 200-208. 
Kaspar, T. C., and W. L. Bland, (1992) : Soil temperature and root growth. Hort Science, 33, 947-951.

Kurian, J., and Vinajachandran, P. N., (2006) : Formation mechanisms of temperature inversion in the southeastern Arabian Sea, Res. Lett., 33. L17611.

Lukatkin A. S., Brazaityte A., Bobinas C., Duchovskis P., (2012) : Chilling injury in chilling sensitive plants : a review. Agriculture 99 111-124.

Marshall, T. J. and J. W. Holmes, (1988) : Soil Physics. $2^{\text {nd }}$ ed. Cambridge Univ. Press, New york.

Oke, T. R., (1987) : Boundary Layer Climates, Second Edition, Cambridge University Press.

Rezuana Islam, (2017) : A comparative study on the variation of soil temperature at different depths, Int. Journal of Scientific \& Engeneering Research, Volume 8, 444-446.

Smith, Erik T., and S. C. Sheridan, (2018) : The characteristics of extreme cold events and cold air outbreaks in the eastern united states. Int. J. Climatol.

Storch, H. V. and Francis, W.Z. (2001): Statistical Analysis in climate Research, first edition, Cambridge university press, 197- 215.

Thadathil, L., and Gosh, A. K., (1992) : Surface Layer temperature inversion in the Arabian Sea during winter, J. Oceanogr., 48(3), 239-304.

Thadathil, L., and others, (2016) : Surface layer temperature inversion in the Bay of Bengal : Main characteristics and related mechanisms, American Geophysical Uonion.

Thom, H.C.S. (1996) : Some methods of climatological Analysis. WMO Technical note NO. 81, WMO- NO. 199. T. P. 103, Geneva, Switzerland.

Veronica Munoz-Romero, Luis Lopez-Bellido, and Rafael J. Lopez-Bellido, (2015) : Effect of tillage system on soil temperature in rainfed Mediterranean Vertisol, Int. Agrophys., 29, 467-473.

Wilks, D.S. (2001) : Statistical Methods in the Atmospheric sciences An Introduction, International Geophysics series, volume 59, 41 - 63. 
مجلة جامعة مصر اتة للعلوم الزراعية

عدد خاص بالأوراق العلمية المقدمة للمؤتمر العلمي الأول للعلوم الزراعية - إنتاج نباتي (5-6 أكتوبر 2019)

\title{
Diurnal Variability of Soil and Air temperature as a function of time and depth, A case study of the cold wave that hit Zawia region during the period 1-5 February 1999
}

\author{
Abdelfatah Hadi Shibani \\ Authority of Natural Science Research and Technology, Tripoli - Libya \\ Afshibani@gmail.com
}

https://doi.org/10.36602/jmuas.2019.v01.01.12

\begin{abstract}
Soil temperature is one of the important variables in agricultural studies, which is necessary to be measured and analyze. There are some major challenges facing a lot of agricultural studies focus on soil temperature in Libya, such as, the soil temperature is measured only at Agro meteorological stations in the country, the lack of stations, the measurement of soil temperature is a cumbersome business and not as simple as air temperature be noted by single thermometer, Separate thermometers are required to measure the temperature of the soil at different depths, the installation of thermometer sensor correctly in the soil is another very complicated technical matter. However, in Libya there are no enough studies into the pattern of hourly variation in soil temperature over twenty-four hours due to the lack of such measurements at agricultural lands. So that, this attempt has been made to diagnose the behavior of soil temperature and air temperature as a case study, This work was carried out by using the daily and hourly data recorded for the temperature in the standard depths of soil $(5,10,20,30,50,100 \mathrm{~cm})$, and the surface air temperature at heights of $(5,10,15,50,100,150,200 \mathrm{~cm})$, Data were measured, Reported and collected every three hours interval during the period from 01 to 05 February 1999, at Zawia Agro-Meteorological Station where the location of the station was under the effect of cold wave. The data were measured on a daily basis at 0000,0300 , 0600, 0900, 1200, 1500, 1800, 2100 UTC. The correlation coefficient between the hourly soil temperature and hourly air temperature at certain depths and heights were calculated using the Pearson's Formula, then the matrix of correlation factors have been derived, The vertical profile for the hourly variation of temperature in the layer between $100 \mathrm{~cm}$ under the surface of soil and $200 \mathrm{~cm}$ above the surface of soil have been described, Graphs and tables were done to show more explanation. The analysis of the observation shows that soil temperature variability decreases with depth, the highest temperature variability in top soil, and the lowest one is deeper than $50 \mathrm{~cm}$. These results were affected due to the prevailing weather situation because at night time there is no enough solar radiation and the ambient temperature is lower than soil temperature. As a result, the soil temperature transferred heat from soil to atmosphere above. In addition, the low thermal conductivity of the soil is also one important factor that affects heat storage. These results demonstrated the importance of monitoring the soil temperature as an important element for agricultural studies. The results of the present paper could fill in some of the gap related to the soil temperature studies in Libya, and can be used for planning agronomic and plant protection practices.
\end{abstract}

